\title{
CONTAMINACIÓN URBANA DE LOS CUERPOS DE AGUA EN LA AMAZONIA PERUANA
}

\author{
M. Rosario Gómez Garcia *
}

\section{RESUMEN}

El estudio sobre la contaminación ambiental en los cuerpos de agua de la Amazonía Peruana recoge las evaluaciones de la calidad de las aguas en base a los aspectos físicos, químicos y microbiológicos.

La investigación ha abarcado los cuerpos de agua que circundan las ciudades de Tarapoto, Pucallpa e Iquitos.

Las mediciones fueron hechas a lo largo del año 1994, en época de creciente (mayo y junio) y de vaciante (setiembre) en Iquitos, en vaciante (agosto) en Pucallpa y en la época de media creciente (noviembre) en Tarapoto.

El monitoreo físico-químico indica la existencia de contaminación por hidrocarburos en varios de los puntos muestreados, en menor proporción existe también contaminación por plomo, arsénico, cromo y fenoles sólo en algunos puntos de estos cuerpos de agua.

El monitoreo microbiológico indica una alta contaminación por coliformes totales y fecales en la casi totalidad de los cuerpos de agua muestreados en las tres ciudades.

\begin{abstract}
The study of pollution in bodies of water in the Peruvian Amazon region collects the evaluation of the quality of the waters on the basis of their physical, chemical and microbiological aspects.
\end{abstract}


The research has included the bodies of water around the cities of Tarapoto, Pucallpa and Iquitos.

The measurements were made throughout 1994 at a time of high tide (May and June) and low (September) in Iquitos and mid-high (November) in Tarapoto

The physical-chemical monitoring indicate the existence of pollution due to hydrocarburates in several sample sites; there is also pollution by lead, arsenic, chrome and phenols in a lesser degree and only in some parts of these bodies of water.

The microbiological monitoring indicate high levels of pollution by total and fecal coliforms in most of the bodies of water in three cities.

\section{INTRODUCCION}

La calidad "natural" de las aguas de la Amazonía difiere de unos cuerpos de agua a otros, de acuerdo con las condiciones físico-químicas que las caracteriza, según se trate de cuerpos de aguas negras, blancas o claras; en general son aguas poco mineralizadas, clasificadas como blandas o semiduras.

Los ríos de agua blanca tales como el Amazonas, Ucayali, Marañón, Napo, Pastaza, etc, se caracterizan por presentar un $\mathrm{pH}$ neutro, alta turbidez y alcalinidades entre 42 y $142 \mathrm{mg} / \mathrm{L}$.

Los ríos de agua clara tales como el Tigre, Macusari, Corrientes, etc, presentan baja turbidez, $\mathrm{pH}$ ácido y alcalinidad entre 7 y $50 \mathrm{mg} / \mathrm{L}$.

Los ríos de aguas negras tales corno el Pacaya, Samiria, Chambira, Nanay, Itaya, etc, presentan baja turbidez, alcalinidades entre 10 y $50 \mathrm{mg} / \mathrm{L}$ y $\mathrm{pH}$ ácidos.

Para determinar la calidad del agua se ha hecho necesario establecer normas de calidad. Las normas de calidad representan la concentración o nivel determinado que debe tener una sustancia, un elemento o un compuesto presente en el agua a utilizar. Cuando esta concentración se mantiene dentro de unos límites definidos, que se han considerado como adecuados, su consumo o utilización no debe ser nocivo para los organismos o los ecosistemas; igualmente debe ser apta para un determinado uso, ya sea éste doméstico, agrícola, industrial, de recreación, etc. 
En la Amazonía Peruana las normas de calidad del agua vienen establecidas por los valores limites que recoge la Ley General de Aguas para los diferentes usos y los distintos parámetros.

Por otro lado, la región de la selva peruana pasa por un acelerado proceso de concentración urbana. Así, las ocho principales ciudades amazónicas albergan el $30 \%$ de la población total de la región y la población urbana asciende al $48,8 \%$ del total (Webb y Fernández-Baca, 1991).

Según el censo poblacional de 1993, en selva baja, la ciudad de Iquitos cuenta con 274759 habitantes; en selva media y alta, Pucallpa llega a 172288 y Tarapoto a 77783 habitantes.

Ninguna de estas ciudades hace tratamiento de sus aguas servidas, las que van a parar directamente a los ríos que las circundan, los cuales proveen de agua a las poblaciones que se encuentran a su paso.

Las industrias de todo tipo, pero en especial los aserraderos y otras industrias forestales, arrojan sus desperdicios directamente a los ríos o proceden a quemarlos parcialmente, contaminando el aire urbano. Asimismo, las instalaciones portuarias y la navegación fluvial vierten sus residuos y limpian sus depósitos sobre ríos y cochas. El presente estudio recoge las evaluaciones de la calidad de las aguas basadas en análisis físico-químicos y bacteriológicos de los cuernos de agua adyacentes a las ciudades de Iquitos, Pucallpa y Tarapoto, realizadas durante 1994.

\section{MATERIAL Y METODOS}

\section{1 Áreas de estudio}

Como áreas de estudio se seleccionaron los ríos y cochas circundantes las tres ciudades más grandes de la Amazonía, corno son Iquitos, Tarapoto y Pucallpa, para observar la influencia que los desechos urbanos y las aguas servidas de estas ciudades tienen sobre la calidad del agua.

En la ciudad de Iquitos, se muestrearon los ríos Amazonas, ltaya, Nanay, así como el lago Moronacocha y la laguna de Rumococha.

Además, el déficit en el abastecimiento de agua potable ha originado que los pobladores hayan construido pozos artesanales para abastecerse de agua. 


\subsection{Técnicas de muestreo}

En la determinación de las estaciones de muestreo se han considerado los puntos con problemas de contaminación o puntos aguas arriba y aguas abajo de un vertido; asimismo, en los cuerpos de agua de las ciudades, se ha tomado en cuenta los puntos de torna de agua para abastecer a la población.

Los muestreos se han realizado por toma de muestras simples.

A continuación, se especifican los puntos de muestreo en cada cuerpo de agua.

\subsubsection{Cuerpos de agua de Iquitos}

Por lo que respecta a la determinación de la calidad del agua de los ríos circundantes la ciudad de Iquitos, se han realizado dos muestreos, el primero en los meses de mayo y junio y el segundo en el mes de setiembre, exceptuando la laguna de Rumococha en la que el primero se realizó en el mes de abril y el segundo en el mes de agosto.

Los muestreos se han realizado en los distintos cuerpos de agua y puntos - que se indican a continuación (ver Figura 1):

\section{- Río Amazonas:}

- Frente al Hotel de Turistas, después de la desembocadura del río ltaya.

- Frente a la central térmica de Electro Oriente.

- $\quad$ Frente al puerto fluvial de Iquitos (ENAPU).

- Frente a la refineria.

- Río Itaya:

Frente al molino ECASA.

Frente al desagüe de hospitales (Sachachorro).

Frente a la Prefectura. 
- Río Nanay:

Frente al club Caza y Pesca.

En la zona de captación para el agua potable (Pampachica).

En la desembocadura del lago de Moronacocha.

\section{- Lago Moronacocha:}

Zona del cavado de la cocha.

Frente al puente Morona.

Frente a la gasolinera.

En la salida de la cocha por la laguna de la pradera.

\section{- Laguna de Rumococha:}

Entrada del río Nanay a la cocha.

Frente a la barcaza.

Frente a Forestal Amazonas.

\subsubsection{Cuerpos de agua de Tarapoto}

Para el estudio de la calidad de las aguas en la ciudad de Tarapoto, se ha realizado un muestreo en el mes de noviembre.

Los puntos de muestreo están localizados en las siguientes zonas (Figura 2):

\section{- Río Shilcayo:}

Bocatoma de captación del agua para la ciudad. Aguas abajo del Tecnológico.

\section{- Quebrada Ahuasbiyacu:}

Bocatoma del canal de irrigación.

Bocatoma de la granja San Borja:

\section{- Río Cumbaza:}

Frente a San Pedro Cumbaza.

Bocatoma de la irrigación. 
Zona de Juan Guerra.

- Río Mayo:

Frente a la población de Shanao.

Puente Colombia.

- Río Huallaga:

Zona de Shapaja. Después de la confluencia con el río Mayo.

Zona de Buenos Aires. Antes de la confluencia con el río Mayo.

\subsubsection{Cuerpos de agua de Pucallpa}

Para el estudio de la calidad de las aguas en Pucallpa se ha realizado un muestreo en el mes de agosto.

Los puntos de muestreo están localizados en las siguientes zonas (Figura $3)$ :

- Laguna de Yarinacocha:

Frente al poblado Nueva Luz.

Frente al puerto Callao.

Frente al caño cashibo.

- Quebrada Manantay:

En el caño de captación del agua para la planta de tratamiento.

- Pozos comunales:

Urbanización Pedro Portillo.

- Asentamiento humano Roberto Ruiz Vargas. Calle San Francisco del Aguila.

- Pueblo Joven Las Palmeras. Calle Las Palmeras con Micaela.

- Pueblo Joven 9 de octubre. Calle Lloque Yupanqui con 28 de Julio. 


\subsection{Técnicas de análisis}

\subsubsection{Análisis físico-químicos}

La determinación de los parámetros que siguen a continuación se realizaron in situ: temperatura del agua, oxígeno disuelto, conductividad y $\mathrm{pH}$.

Para los análisis de laboratorio se tomaron muestras en dos frascos de vidrio y/o de polietileno, preservando una de ellas con ácido nítrico, para el análisis de metales. Estos análisis fueron realizados en el laboratorio de Química Analítica de la IJNAP, por métodos estándares.

\subsubsection{Análisis bacteriológicos}

Las muestras de agua fueron tomadas en frascos de $250 \mathrm{ml}$, esterilizados proporcionados por los laboratorios que realizaron los análisis.

Las muestras de los cuerpos de agua circundantes la ciudad de Iquitos fueron analizadas en el laboratorio del Instituto Veterinario de Investigaciones Tropicales y de Altura (IVITA). Se determinó el número más probable de coliformes totales y fecales por mililitro, por el método norteamericano. Para la determinación de coliformes totales se utilizó el medio de cultivo caldo lauril sulfato, con diluciones 10-1, 10-2 y 10-3. Para la determinación de coliformes fecales se utilizaron los medios de cultivo caldo lauril sulfato, caldo brila y caldo triptonado, con diluciones 10-110-2y 10-3.

En las muestras de los cuerpos de agua circundantes a las ciudades de Pucallpa y Tarapoto se han determinado las unidades formadoras de colonias de coliformes totales y fecales, por mililitro, por el método de recuento de placas (SPC).

En Pucallpa se analizaron en el laboratorio del Instituto Nacional de Investigación Agraria (INIA) y en Tarapoto en el Laboratorio Regional Referencial de Salud Pública. 


\section{RESULTADOS}

\subsection{Calidad de las aguas de Iquitos}

Los resultados obtenidos de los cuerpos de agua de Iquitos se presentan en los Cuadros 1 y 2 .

Desde el punto de vista físico-químico en el río Amazonas, en la Estación 1 después de la desembocadura del no Itaya, en el primer muestreo encontramos un contenido de oxigeno disuelto bajo (2,9 ppm), por debajo de los límites para todos los usos del agua (Cuadro 5). En la Estación frente a ENAPIJ el contenido de sólidos totales disueltos se encontró por encima del valor limite para el agua potable, según la Organización Mundial de la Salud (OMS).

Asimismo, se encontró contaminación por fenoles frente a la Refinería, con un valor muy por encima de los límites para todos los usos del agua.

Por otro lado, frente a Electro-Oriente, ENAPU y la Refinería se encontraron altos niveles de hidrocarburos, por encima de los límites para todos los usos del agua.

En la época de vaciante se encontró contaminación por hidrocarburos frente a la Refinería con un valor por encima de los usos del agua para riego de vegetales de consumo crudo y para agua de zonas recreativas de contacto primario. En el mismo punto también se encontró presencia de plomo, pero con un valor por debajo de los límites máximos permisibles. 


\title{
Cuadro 1. Análisis físico-químicos y bacteriológicos de los cuerpos de agua circundantes Iquitos (ríos: Amazonas, Itaya y Nanay; lagos: Moronacocha). Abril -mayo-junio,1994.
}

\begin{tabular}{|c|c|c|c|c|c|c|c|c|c|c|c|c|c|c|c|c|}
\hline \multirow[t]{2}{*}{ PARAMETROS } & \multicolumn{16}{|c|}{ ESTACIONES DE MUESTREO } \\
\hline & Al & A2 & A3 & A4 & 11 & 12 & 13 & NI & N2 & N3 & MI & $\mathrm{M} 2$ & M3 & RI & $\mathrm{R} 2$ & R3 \\
\hline $\mathrm{T}$ agua ${ }^{\circ} \mathrm{C}$ & 25,5 & 25 & 25 & 25,5 & 26 & 26.5 & 27 & 26 & 27 & 28 & 26 & 27 & 26 & 23,5 & 20 & 21,5 \\
\hline $\mathrm{pH}$ & 6,0 & 6,3 & 6,5 & 6,0 & 6,5 & 5,8 & 6,0 & 6.5 & 6,5 & 6,6 & 6.6 & 6,5 & 6,6 & 6,3 & 6,4 & 6,4 \\
\hline Conductividad homs/cm & 130 & 149 & 143 & 137 & $\cdots$ & 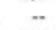 & - & $\cdots$ & - & - & - & - & - & 10 & 5 & 5 \\
\hline Oxigeno disuelto ppm & 2,9 & 3,6 & 3,8 & 3,8 & 2,0 & 1,6 & 2,3 & 2.5 & 3,0 & 4.2 & 2,6 & 1.4 & 1.7 & 2,8 & 3 & 3.8 \\
\hline S.T.D. ppm & 970 & 990 & 1110 & 710 & 760 & 880 & 900 & 100 & 200 & 150 & 200 & 100 & 239 & -. & - & - \\
\hline Alcalinidad ppm & - & - & -. & $\cdots$ & $\cdots$ & -. & - & 4,5 & 2,5 & 3,0 & 1,75 & 4,0 & 5,5 & 15 & 10 & 10 \\
\hline Dureza total ppm & 48 & 51 & 52,5 & 54,5 & 42,5 & 47,5 & 44 & 2,0 & 1,5 & 2,0 & 1,5 & 2,0 & 1,5 & 3 & 2,5 & 2 \\
\hline Nitratos ppm & 0,0 & 0,0 & 0,0 & 0,0 & 0,0 & 0,02 & 0,0 & 0,0 & 0,0 & 0,0 & 0,0 & 0,0 & 0,0 & .. & - & -. \\
\hline Fenoles ppm & 0,0 & 0,0 & 0.0 & 4,0 & 0,0 & 0,0 & 0.0 & 0.0 & 0,0 & 0.0 & 0,0 & 0.0 & 0,0 & 0,0 & 0,0 & 0,0 \\
\hline Hidrocarburos ppm & 0,0 & 3,0 & 4.5 & 7,0 & 0,0 & 0,0 & 0,0 & 2,5 & 0,0 & 2,0 & 2,5 & 5,0 & 2,3 & 3 & 8 & 3 \\
\hline Zine ppm & 0,04 & 0,07 & 0,0 & 0,01 & 0,0 & 0,03 & 0,02 & 0,01 & 0,007 & 0,007 & 0,004 & 0,001 & 0,001 & -. & - & - \\
\hline Plomo ppm & 0,0 & 0.0 & 0.0 & 0,0 & 0,0 & 0.0 & 0,0 & 0,0 & 0,0 & 0.0 & 0,0 & 0.0 & 0,0015 & 0,005 & 0,015 & 0,002 \\
\hline Arsénico ppm & 0,0 & 0,0 & 0,0 & 0,0 & 0,0 & 0,0 & 0,0 & 0.0 & 0.0 & 0.0 & 0.0 & 0,0 & 0,0 & 0,001 & 0,001 & 0.003 \\
\hline Coli. totales NMP/ml & 1100 & 1100 & 1100 & 1100 & 21 & 1100 & 210 & 1100 & 1100 & 1100 & 40 & 1100 & 1100 & 11 & 7 & 0,0 \\
\hline Coli. Fecales NMP/mI & 950 & 950 & 950 & 950 & 20 & 950 & 200 & 1100 & 1100 & 1100 & 40 & 1100 & 1100 & 11 & 7 & 0,0 \\
\hline
\end{tabular}

\footnotetext{
A3 : Río Amazonas frente a ENAPU

I1 : Río Itaya frente al molino ECASA

13 : Río ltaya frente a la prefectura

N2 : Río Nanay. Pampachica

MI : Moronacocha, en el cayado de la cocha

M3 : Moronacocha frente a la gasolinera

R2 : Rumococha frente a la barcaza hundida
}

\author{
A2 : Río Amazonas frente a Electro -Oriente \\ A4 : Río Amazonas frente a la Refinería \\ I2 : Río Itaya después del desague de sachachorro \\ N1 : Río Nanay frente al club de Caza y Pesca \\ N3 : Río Nanay frente al caño de Moronacocha \\ M2 : Moronacocha frente al puente \\ Rl : Rumococha. entrada del río a la cocha \\ R3 : Rumococha frente al aserradero Forestal Amazonas
}

Desde el punto de vista bacteriológico en los dos muestreos realizados se encontró una alta contaminación de coliformes totales y fecales, por encima de los limites para todos los usos del agua.

En el río Itaya, en la época de creciente, se encontraron bajos niveles de oxigeno disuelto en las tres estaciones de muestreo.

Desde el punto de vista bacteriológico, en la época de creciente, se presentó una alta contaminación de coliformes totales y fecales después del desague de Sachachorro y frente a la prefectura. En la época de vaciante, en las tres estaciones de muestreo, se encontró una alta' contaminación de coliformes totales y fecales, por encima de los límites permisibles para todos los usos de agua. 
En el río Nanay, en la época de creciente, se presenté un bajo nivel de oxígeno disuelto frente al club Caza y Pesca. Asimismo, se encontré contaminación por hidrocarburos por encima de los límites premisibles para todos los usos del agua, en los puntos frente al club Caza y Pesca y frente al caño de Moronacocha.

En la época de vaciante se encontré la presencia de hidrocarburos en Pampachica, pero su valor está dentro de los límites permisibles.

\section{Cuadro 2. Análisis físico-químicos y bacteriológicos de los cuerpos de agua circundantes Iquitos (ríos: Amazonas, Itaya, Nanay; lagos: Moronacocha y Rumococha). Agosto-setiembre, 1994.}

\begin{tabular}{|c|c|c|c|c|c|c|c|c|c|c|c|c|c|c|c|c|}
\hline \multirow[t]{2}{*}{ PARAMETROS } & \multicolumn{16}{|c|}{ ESTACIONES DE MUESTREO } \\
\hline & Al & $\mathrm{A} 2$ & A3 & A4 & II & 12 & 13 & N1 & $\mathrm{N} 2$ & N3 & M1 & M2 & M3 & RI & R2 & R3 \\
\hline Temp. Agua ${ }^{\circ} \mathrm{C}$ & 28 & 28 & 28 & 29 & 27 & 27.5 & 27 & 28 & 28 & 31 & 26 & 26 & 27 & 28 & 28 & 28 \\
\hline $\mathrm{pH}$ & 7 & 6,5 & 5,9 & 6 & 6 & 6.5 & 6,5 & 6.5 & 6,3 & 6.5 & 7 & 6.7 & 6,5 & 6,5 & 6,4 & 6,9 \\
\hline Oxig. Disuelto ppm & 5,8 & 5,9 & 5,9 & 5 & 4,8 & 3,9 & 4,7 & 4,7 & 4,7 & 4,8 & 3,8 & 3,2 & 5.9 & 2,3 & 2,1 & 2,3 \\
\hline STD ppm & 198 & 280 & 295 & 298 & 180 & 195 & 20,5 & 109 & 104 & 110 & 250 & 285 & 197 & 135 & 155 & 120 \\
\hline Alcalinidad ppm & 24,5 & 60,5 & 69 & 69,5 & 20,5 & 23 & 25 & 2 & 3,25 & 6 & 72 & 87 & 15 & 6.5 & 7,5 & 7,5 \\
\hline Dureza total ppm & 63.5 & 73 & 75 & 78 & 17 & 18 & 21,5 & 1 & 1 & 4 & 36 & 72 & 14 & 5 & 7,5 & 5 \\
\hline Nitratos ppm & 1,95 & 3 & 3 & 3 & 1,5 & 3 & 1.8 & 0,0 & 0,0 & 0,0 & 0,2 & 1,08 & 0,2 & 2 & 1 & 2 \\
\hline Fosfatos ppm & 0.05 & 0,03 & 0,03 & 0,03 & 0,03 & 0,005 & 0,02 & 0,0 & 0,0 & 0,0 & 0,02 & 0,03 & 0,0 & 0,005 & 0,005 & 0,005 \\
\hline Sulfatos ppm & 0,0 & 0,8 & 0,0 & 0,08 & 0,0 & 0,0 & 0,0 & 0,1 & 0,0 & 0,0 & 0.5 & 1,5 & 0,0 & 5 & 6 & 5 \\
\hline Fenoles ppm & 0,0 & 0,0 & 0,0 & 0,0 & 0.0 & 0,0 & 0,0 & 0.0 & 0,0 & 0.0 & 0,0 & 0,0 & 0,0 & 0,0 & 0,0 & 0,0 \\
\hline Hidrocarburos ppm & 0,0 & 0,0 & 0,0 & 1,25 & 0,0 & 0,0 & 0,0 & 0,0 & 0.2 & 0,0 & 0,0 & 0,0 & 0,0 & 2,1 & 2,5 & 1,2 \\
\hline Plomo ppm & 0,0 & 0,0 & 0,0 & 0,001 & 0,0 & 0,0 & 0.0 & 0.0 & 0,0 & 0,0 & 0,0 & 0,0 & 0,0 & 0,001 & 0,002 & 0,002 \\
\hline Arsénico ppm & 0,0 & 0,0 & 0,0 & 0,0 & 0,0 & 0,0 & 0,0 & 0,0 & 0,0 & 0,0 & 0,0 & 0.0 & 0,0 & 0,003 & $0,0015 \mathrm{c}$ & 0,0015 \\
\hline Coli. totales NMP/ml & 850 & 780 & 1000 & 1100 & 1100 & 1000 & 1000 & 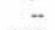 & - & $\ldots$ & - & 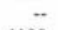 & - & - & 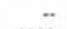 & -. \\
\hline Coli. fecales IINMP/ml & 520 & 480 & 810 & 980 & 750 & 810 & 710 & 1100 & 14 & 23 & 1100 & 1100 & 1100 & 20 & 1100 & 1100 \\
\hline
\end{tabular}

Al : Río Amazonas después de la boca del Itaya

A3: Río Amazonas frente a ENAPIJ

11: Río ltaya frente al molino ECASA

13: Río ltaya frente a la prefectura

N2: Río Nanay, Pampachica, toma de agua

MI: Moronacocha, en el cavado de la cocha

M3: Moronacocha en la laguna de la pradera

R2: Rumococha frente a la barcaza hundida
A2 : Río Amazonas frente a Electro-Oriente

A4 : Río Amazonas frente a la Refinería

12: Río haya después del desague del Sachachorro

N1 : Río Nanay frente al club de Caza y Pesca

N3: Río Nanay frente al caño de Moronacocha para la ciudad

M2: Moronacocha frente al puente

Rl : Rumococha, entrada del río a la cocha

R3 : Rumococha frente al aserradero Forestal Amazonas

Desde el punto de vista bacteriológico, en la época de creciente, se presentó una alta contaminación de coliformes totales y fecales; en vaciante también hubo una alta contaminación por coliformes fecales por encima de los limites para agua de consumo humano directo.

En la laguna de Moronacocha, en la época de creciente, se encontraron bajos niveles de oxígeno disuelto en las tres estaciones de muestreo. Asimismo, en los 
tres puntos de muestreo, se encontró contaminación por hidrocarburos con unos valores por encima de los limites permisibles para todos los usos del agua. También se presentó plomo frente a la gasolinera, pero su valor está dentro de los limites permisibles.

Desde el punto de vista bacteriológico, en la época de creciente, se encontraron altos niveles de coliformes totales y fecales frente al puente y frente a la gasolinera; en la época de vaciante se observaron altos niveles de coliformes fecales en los tres puntos de muestreo.

En la laguna de Rumococha, en la época de creciente, se encontró bajo nivel de oxigeno en la entrada del río Nanay; asimismo, se presentó alta contaminación por hidrocarburos en las tres estaciones de muestreo, por encima de los límites permisibles para todos los usos del agua. También se observó la presencia de los metales pesados plomo y arsénico en los tres puntos de muestreo, pero sólo los valores de plomo en la entrada del no Nanay y frente a la barcaza hundida están por encima de los limites permisibles para aguas de zonas de preservación de fauna acuática y pesca.

En la época de vaciante, en los tres puntos muestreados se encontraron bajos niveles de oxigeno disuelto. La contaminación más alta por hidrocarburos se encontró en la entrada del río a la cocha y frente a la barcaza hundida, con valores por encima de los límites permisibles para todos los usos del agua; del mismo modo se observó la presencia de plomo y arsénico pero con valores dentro de los límites permisibles.

Desde el punto de vista bacteriológico, en la época de creciente, los valores de coliformes totales y fecales que se presentan en la entrada del río Nanay y frente a la barcaza hundida son muy altos, siendo esta agua no apta para consumo y contacto directo. Sin embargo, los valores de coliformes fecales, en la época de vaciante, son muy altos frente a la barcaza hundida y frente al aserradero forestal Amazonas, estando por encima de lo máximo permisible para todos los usos del agua. 


\subsection{Calidad de las aguas en Tarapoto}

Los resultados obtenidos en los cuerpos de agua de Tarapoto se presentan en el Cuadro 3.

Desde el punto de vista químico, en los cuerpos de agua muestreados en la ciudad de Tarapoto, se encontró contaminación por nitratos en el río Shilcayo (35 ppm), aguas abajo del tecnológico; dicho valor se encuentra por encima de los límites permisibles para el agua potable, según la OMS. Asimismo, en el no Huallaga, en la zona de Buenos Aires, se encontró la presencia de cromo, pero con un nivel dentro de los límites premisibles por la Ley General de Aguas (Cuadro 5).

Desde el punto de vista bacteriológico, se presentó una alta contaminación por coliformes totales en todas las estaciones muestreadas, a excepción de la bocatoma de agua para la ciudad (río Shilcayo) y en el no Huallaga, en la zona de Buenos Aires. Del mismo modo se observó contaminación por coliformes fecales en el río Shilcayo (aguas abajo del tecnológico), en el río Cumbaza (en la bocatoma de irrigación y en San Pedro de Cumbaza) y en el río Mayo (en Shanao y en Puente Colombia).

\subsection{Calidad de las aguas en Pucallpa}

Los resultados de los cuerpos de agua muestreados en la ciudad de Pucallpa se presentan en el Cuadro 4.

De los cuerpos de agua muestreados en la ciudad de Pucallpa, en la laguna de Yarinacocha se observó presencia de hidrocarburos, frente al puerto Callao, su valor se encuentra dentro de los límites permisibles para el agua de consumo humano, pero por encima del nivel máximo permitido para agua de zonas recreativas de contacto primario. Asimismo, también se observó presencia de plomo en las tres estaciones de muestreo, pero sus valores se encuentran dentro de los límites permisibles.

Desde el punto de vista bacteriológico se encontró la presencia de coliformes totales pero no de coliformes fecales.

En la quebrada Manantay, en el punto de captación de agua para la ciudad, se encontró contaminación por nitratos e hidrocarburos; para ambos parámetros los niveles estaban por encima de los límites permisibles para agua de consumo 
humano. Desde el punto de vista bacteriológico, se presentaron valores muy altos de coliforrnes totales y fecales.

Cuadro 3. Análisis físico-químicos y bacteriológicos de los ríos adyacentes a Tarapoto (Shilcayo, Ahuashiyacu, Cumbaza, Mayo y Huallaga). Noviembre 1994.

\begin{tabular}{|c|c|c|c|c|c|c|c|c|c|c|c|}
\hline \multirow[t]{2}{*}{ PARAMETROS } & \multicolumn{11}{|c|}{ ESTACIONES DE MUESTREO } \\
\hline & S1 & $\mathrm{S} 2$ & Al & A2 & $\mathrm{Cl}$ & $\mathrm{C} 2$ & $\mathrm{C} 3$ & M1 & M2 & $\mathrm{HI}$ & $\mathrm{H} 2$ \\
\hline Temp. Agua ${ }^{\circ} \mathrm{C}$ & 23 & 31 & 25 & 25 & 20,5 & 20,9 & 22,5 & 23 & 23 & - & -. \\
\hline $\mathrm{pH}$ & 6,5 & 6,5 & 7 & 6 & 6 & 6 & 6 & 6 & 6 & 6,49 & 6,8 \\
\hline Oxig. disuelto ppm & 13,9 & 7,8 & 13,9 & 18,7 & 18,2 & 19,5 & 17 & 17,1 & 16,9 & .. & -. \\
\hline Alcalinidad ppm & 60,5 & 115 & 67,5 & 29 & 10 & 38 & 45,7 & 65 & 77,5 & 10,5 & 15,5 \\
\hline Dureza ppm & 60,5 & 91,5 & 68 & 26 & 16 & 40 & 49,5 & 76 & 91,5 & 71 & 90 \\
\hline Calcio ppm & 35 & 65,5 & 46 & 15 & 6 & 29 & 36,5 & 59 & 77,5 & -. & - \\
\hline Sulfatos ppm & 40 & 70 & 40 & 10 & 5 & 3 & 10 & 5 & 5 & 20 & 20 \\
\hline Fosfatos ppm & 10 & 25 & 10 & 5 & 10 & 5 & 5 & 5 & 5 & -. & 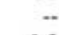 \\
\hline Nitratos ppm & 0,0 & 35 & 0,0 & 0,0 & 10 & 5 & 5 & 5 & 5 & 1 & 0,8 \\
\hline Hidrocarburos ppm & 0,0 & 0,0 & 0,0 & 0,0 & 0,0 & 0,0 & 0,0 & 0,0 & 0,0 & 0,0 & 0,0 \\
\hline Plomo ppm & 0,0 & 0,0 & 0,0 & 0,0 & 0,0 & 0,0 & 0,0 & 0,0 & 0,0 & 0,0 & 0,0 \\
\hline Cromo ppm & 0,0 & 0,0 & 0,0 & 0,0 & 0,0 & 0,0 & 0,0 & 0,0 & 0,0 & 0,0 & 0,001 \\
\hline Coli totales UFC/ml & 34 & 9000 & 7700 & 22000 & 690 & 600 & 1100 & 4100 & 830 & 2500 & 42 \\
\hline Coli fecales UFC/ml & 0,0 & 36 & 0,0 & 0,0 & 14 & 21 & 0,0 & 10 & 0,0 & 0,0 & 0 \\
\hline
\end{tabular}

SI: Río Shilcayo, bocatoma de agua para la ciudad.

S2 : Río Shilcayo aguas abajo del Tecnológico.

$\mathrm{Al}$ : Quebrada Ahuashiyacu, bocatoma del canal de irrigación.

A2:Quebrada Ahuashiyacu, bocatoma la granja San Borja.

$\mathrm{Cl}$ : Río Cumbaza en San Pedro de Cumbaza.

C2: Río Cumbaza, bocatoma de irrigación.

C3 : Río Cumbaza en Juan Guerra.

MI: Río Mayo en Shanao.

M2: Río Mayo en puente Colombia.

H1: Río Huallaga. zona de Shapaja, después de la confluencia del río Mayo.

H2 : Río Huallaga, zona de Buenos Aires, antes de la confluencia con el río Mayo.

De los cuatro pozos muestreados, en los de los pueblos jóvenes Las Palmeras y Nueve de Octubre, se encontró contaminación por nitratos con valores por encima del limite recomendado por la OMS para el agua potable. Asimismo, en estos dos pozos se encontró contaminación por coliformes totales y fecales. 


\section{DISCUSION DE LOS RESULTADOS}

En los cuernos de agua adyacentes a la ciudad de Iquitos los niveles de oxígeno disuelto se han presentado con valores más bajos en la época de creciente, en todos los puntos de muestreo, pudiendo deberse a que la carga de sedimentos en el agua en esta época es mayor no permitiendo fácilmente la transferencia de oxígeno entre la atmósfera y el agua. De igual modo, puede deberse a la mayor contaminación encontrada en esta época, ya que los procesos de autodepuración que se llevan a cabo en el río consumen oxígeno.

La contaminación por hidrocarburos ha sido más alta en la laguna de Rumococha (8 ppm) y en el río Amazonas (7 ppm) en época de creciente, no habiéndose encontrado este tipo de contaminación en el río Itaya. En general, las concentraciones de hidrocarburos han sido más altas en la época de creciente que de vaciante; esto puede ser debido a que en creciente existe un mayor tráfico fluvial, desapareciendo incluso, en vaciante, en lagunas como Moronacocha, ya que en esta época dicha cocha se vacía completamente, quedando solamente los caños de las aguas servidas de la ciudad que van a desaguar ahí.

También ha podido deberse al derrame de crudo que se produjo en la laguna de Rumococha en esta época, lo que hizo que aumentaran las concentraciones de hidrocarburos en el lugar. 


\section{Cuadro 4. Análisis físico-químicos y bacteriológicos de los cuerpos de agua adyacentes a Pucallpa (Yarinacocha, Manantay y pozos comunales). Agosto 1994.}

\begin{tabular}{|c|c|c|c|c|c|c|c|c|}
\hline \multirow[t]{2}{*}{ PARAMETROS } & \multicolumn{8}{|c|}{ ESTACIONES DE MUESTREO } \\
\hline & Y1 & Y2 & $\mathrm{Y} 3$ & MI & P1 & $\mathrm{P} 2$ & P3 & P4 \\
\hline Temp. Agua ${ }^{\circ} \mathrm{C}$ & 32 & 32 & 31 & 15 & 14 & 14 & 15 & 14 \\
\hline Oxig. disuelto ppm & 8 & 8,1 & 8,2 & 14 & 5,5 & 1,8 & 1,5 & 6 \\
\hline Conductividad $\mathrm{H} / \mathrm{cm}$ & 320 & 335 & 286 & 285 & 50 & 160 & 85 & 10 \\
\hline $\mathrm{pH}$ & 8,5 & 8,27 & 8,3 & 7,5 & 7,6 & 7,9 & 7,1 & 7,3 \\
\hline Nitratos ppm & 4,5 & 4,5 & 4,5 & 16 & 4 & 5 & 15 & 15,2 \\
\hline Alcalinidad ppm & 153,4 & 149 & 130,5 & 105,7 & 69 & 72,2 & 51,2 & 30,7 \\
\hline Dureza ppmCaCO3 & 138,5 & 136 & 116,5 & 87,5 & 33 & 37,5 & 26 & 13 \\
\hline S.T.D. ppm & 285 & 272 & 267 & 260 & 105 & 107 & 160 & 125 \\
\hline Sulfatos ppm & 0,0 & 70 & 55 & 50 & 0,0 & 0,0 & 0,0 & 0,0 \\
\hline Hidrocarburos ppm & 0,0 & 0,3 & 0,0 & 2 & 0,0 & 0,0 & 0,0 & 0,0 \\
\hline Plomo ppm & 0,002 & 0,002 & 0,003 & 0,0 & 0,0 & 0,0 & 0,0 & 0,0 \\
\hline Coli totales UFC/ml & 55 & 58 & 58 & 3000 & 0,0 & 8 & 25 & 55 \\
\hline Coli fecales UFC/ml & 0,0 & 0,0 & 0,0 & 1000 & 0,0 & 0,0 & 2 & 1 \\
\hline
\end{tabular}

Y 1 :Yarinacocha, frente a poblado Nueva Luz.

Y2 : Yarinacocha, frente al puerto Callao.

Y3 : Yarinacocba, frente al caño Cashibo.

MI: Quebrada Manantay, en la tuina de agua para la ciudad.

PI : Pozo comunal de la urbanización Pedro Portillo.

P2 : Pozo comunal del asentamiento humano Roberto Ruiz Vargas, calle S. Francisco del Aguila.

P3 : Pozo comunal del pueblo joven Las Palmeras, calle Las Palmeras con Micaela.

P4 : Pozo comunal del pueblo joven Nueve de Octubre, calle Lloque Yupanqui con 28 de Julio.

Los niveles de plomo fueron mayores en Rumococha en todos los muestreos, con un valor mínimo en agosto $(0,002 \mathrm{ppm})$ y máximo en abril $(0,015 \mathrm{ppm})$ debido a la existencia de una mayor concentración de hidrocarburos en el mes de abril.

Contaminación por arsénico sólo se presentó en la laguna de Rumococha ya que en los aserraderos próximos a esta laguna, a veces, se hace tratamiento de la madera con productos quimicos que contienen este metal; los niveles que se encontraron están dentro de los límites permitidos por la Ley General de Aguas.

La contaminación por coliformes fecales ha sido mayor en el río Nanay en época de creciente, con valores de $1100 \mathrm{NMP} / \mathrm{ml}$ en todas las estaciones de muestreo. En

vaciante las concentraciones fueron mayores en la laguna de Moronacocha, con valores de $1100 \mathrm{NMP} / \mathrm{ml}$ en las tres estaciones muestreadas. 
La contaminación por coliforrnes totales fue mayor en la época de creciente, en todos los cuerpos de agua muestreados, con valores máximos de $1100 \mathrm{NMP} / \mathrm{ml}$ (Amazonas, Nanay y Moronacocha) y mínimos de 7 NMP/ml (Rumococha).

Desde el punto de vista bacteriológico el agua no cumple con los valores permisibles de la Ley General de Aguas para aguas de abastecimiento doméstico.

En los cuerpos de agua muestreados en la ciudad de Pucallpa se presentó contaminación por nitratos, hidrocarburos y coliformes totales y fecales.

La contaminación por nitratos presenta niveles más altos en la quebrada Manantay y en los pozos de los pueblos jóvenes Las Palmeras y Nueve de Octubre. La presencia de nitratos en la quebrada Manantay puede ser debida a la descomposición de la materia orgánica procedente de las aguas servidas de la ciudad. En los pozos puede proceder de la disolución de las rocas donde está contenida el agua o de la contaminación por materia orgánica o de una combinación de ambos, ya que dichos pozos están también contaminados por bacterias coliformes, lo cual nos indica una contaminación por aguas negras.

Contaminación por hidrocarburos se ha encontrado en el lago Yarinacocha y en la quebrada Manantay, con mayores valores (2ppm) en esta última. En Yarinacocha los hidrocarburos aparecen solamente en la Estación frente al puerto Callao, debido a las actividades de las embarcaciones en dicho puerto. Su nivel está por encima del permitido por la Ley General de Aguas para aguas de zonas recreativas de contacto primario.

El valor más elevado de coliformes totales se presentó en la quebrada Manantay (3 $000 \mathrm{UFC} / \mathrm{ml}$ ), seguido del lago Yarinacocha, con valores de 55 y $58 \mathrm{UFC} / \mathrm{ml}$. Los

niveles de coliformes totales son mayores en los pozos de los pueblos jóvenes Las Palmeras y Nueve de Octubre, con 25 y 55 UFC/ml, respectivamente.

Contaminación por coliforrnes fecales solamente se presentó en la quebrada Manantay, con $1000 \mathrm{UFC} / \mathrm{ml}$, y en los pozos de los pueblos jóvenes Las Palmeras y Nueve de Octubre, con 2 y $1 \mathrm{UFC} / \mathrm{ml}$, respectivamente. En Manantay proceden de las aguas servidas que son vertidas aguas arriba de la toma de agua; en los pozos nos indica 
que existe contaminación por heces humanas o animales, procedentes posiblemente de filtraciones que se pueden producir desde los sanitarios o fosas sépticas, ya que éstas se encuentran bastante cerca y a la misma profundidad de los pozos.

En los cuerpos de agua muestreados en la ciudad de Tarapoto, se encontró contaminación por nitratos y por coliformes totales y fecales.

La mayor concentración de nitratos se encontró en el río Shilcayo, aguas abajo del Tecnológico, seguida del Cumbaza, en San Pedro de Cumbaza, y en el no Mayo, en puente Colombia.

La contaminación por nitratos puede ser debida a la materia orgánica procedente de las aguas servidas que se vierten en el no Shilcayo y Cumbaza y/o a los residuos de los fertilizantes agrícolas que llegan al agua por el lavado de los suelos.

Contaminación por coliformes totales se encontró en todos los ríos muestreados, los niveles más altos se presentaron en la quebrada Ahuashiyacu (en la bocatoma de la granja San Borja) y en el río Shilcayo (aguas abajo del Tecnológico).

Contaminación por coliformes fecales se presentó en los ríos Shilcayo, Curnbaza y Mayo. Los niveles más altos se encontraron en el río Shilcayo, aguas abajo del Tecnológico (36 UFC/ml) y en el no Mayo, en puente Colombia (30 UFC $/ \mathrm{ml}$ ).

\section{CONCLUSIONES}

Los principales contaminantes en los cuerpos de agua de las ciudades de Pucallpa, Tarapoto e Iquitos son las bacterias coliformes, las cuales suelen ir acompañadas de otros gérmenes patógenos que originan diversas enfermedades intestinales. Ello es debido a que las descargas de las aguas servidas de dichas ciudades se hacen directamente sobre los cuerpos de agua sin ningún tipo de tratamiento; lo que también produce, en algunos puntos, concentraciones de nitratos por encima de los máximos permitidos para agua de consumo humano.

Asimismo, en diversos puntos, se observó contaminación por hidrocarburos originados en las instalaciones portuarias por la navegación fluvial o por derrames ocasionales que se producen en dichos cuerpos de agua, como el ocurrido en Rumococha en 1994. Por el mismo motivo, en muchos de estos puntos también se encuentra la presencia de plomo contenido en el petróleo y sus derivados. 
Por otro lado, en la laguna de Rumococha se presentó contaminación por arsénico procedente de los productos químicos que se usan para el tratamiento de la madera, ya que en dicha cocha existen varios aserraderos $\mathrm{y}$, a veces, el tratamiento de la madera lo hacen cuando ésta se encuentra en las orillas de las cochas.

\section{Cuadro 5. LIMITES MAXIMOS PERMISIBLES SEGUN LA LEY GENERAL DE AGUAS 17752 Y SU MODIFICACION. D.S. 007-83-SA.}

\begin{tabular}{|c|c|c|c|c|c|c|c|}
\hline & \multicolumn{7}{|c|}{ USOS } \\
\hline PARAMETROS & $\mathrm{I}$ & II & III & IV & $\mathrm{V}$ & VI & $(*)$ \\
\hline Nitratos ppm & 0,01 & 0,01 & 0,1 & $\begin{array}{cc}-- & \\
\end{array}$ & NA & NA & 10 \\
\hline Plomo ppm & 0,05 & 0,05 & 0,1 & -- & 0,01 & 0,003 & 0,05 \\
\hline Arsénico ppm & 0,1 & 0,1 & 0,1 & -- & 0,01 & 0,05 & 0,05 \\
\hline Cromo ppm & 0,05 & 0,05 & 1 & -- & 0,05 & 0,05 & 0,05 \\
\hline Zinc ppm & 5 & 6 & 25 & -- & 0,02 & $(* *)$ & 0,05 \\
\hline Oxig. Disuelto ppm & 3 & 3 & 3 & 3 & 5 & 4 & -- \\
\hline Coli. Totales NMP/ml & 0,088 & 200 & 50 & 50 & 10 & 200 & -- \\
\hline Coli. Fecales NMP/ml & 0,0 & 40 & 10 & 10 & 2 & 40 & -- \\
\hline Material extractable en & & & & & & & \\
\hline hexano ppm & 0,0005 & 1,5 & 0,5 & 0,2 & -- & -- & -- \\
\hline Fenoles & $0-9$ & 0,001 & 0,001 & -- & 0,1 & 0,1 & $0,01-0,02$ \\
\hline & & & & & & & 6,5 \\
\hline Dureza total ppm & & & & & & & 500 \\
\hline Calcio ppm & & & & & & & $7 \quad 5-200$ \\
\hline Sólidos totales $\operatorname{ppm}\left(180^{\circ} \mathrm{C}\right)$ & & & & & & & 1000 \\
\hline Sulfatos ppm & & & & & & & 400 \\
\hline
\end{tabular}

Uso 1 : aguas de abastecimiento doméstico con simple desinfección. Uso II aguas de abastecimiento doméstico con tratamiento equivalente a procesos combinados de mezcla, coagulación, sedimentación, filtración y cloración aprobados por el Ministerio de Salud.

Uso III : aguas para riego de vegetales de consumo crudo y bebida de animales. Uso IV aguas de zonas recreativas de contacto primario (baños y similares). Uso V : aguas de zonas de pesca de mariscos bivalvos.

Uso VI : aguas de zonas de preservación de fauna acuática y pesca recreativa o comercial.

límite máximo permisible para el agua potable según la OMS

NA : valor no aplicable.

(**) : pruebas de 96 horas Lc50 multiplicado por 0,02.

Lc50 : dosis letal para provocar 50\% de muertes o inmovilización de la especie del bioensayo. 


\section{BIBLIOGRAFIA}

EL PERUANO. 1983. (17 de marzo). Modifican los Arts. 81 y 82 del Reglamento de los títulos 1, II y III de la Ley General de Aguas. Decreto Supremo 00783- SA.

Instituto de Investigaciones de la Amazonía Peruana. 1988. Contaminación ambiental por actividades petroleras y urbanas. Informe Técnico. Iquitos.

TCA/BID/PNUD. 1992. Amazonía sin mitos.

WEBB, R. y FERNANDEZ BACA, G. 1991. Perú en números, 1991. Lima: CUANTO S.A. 


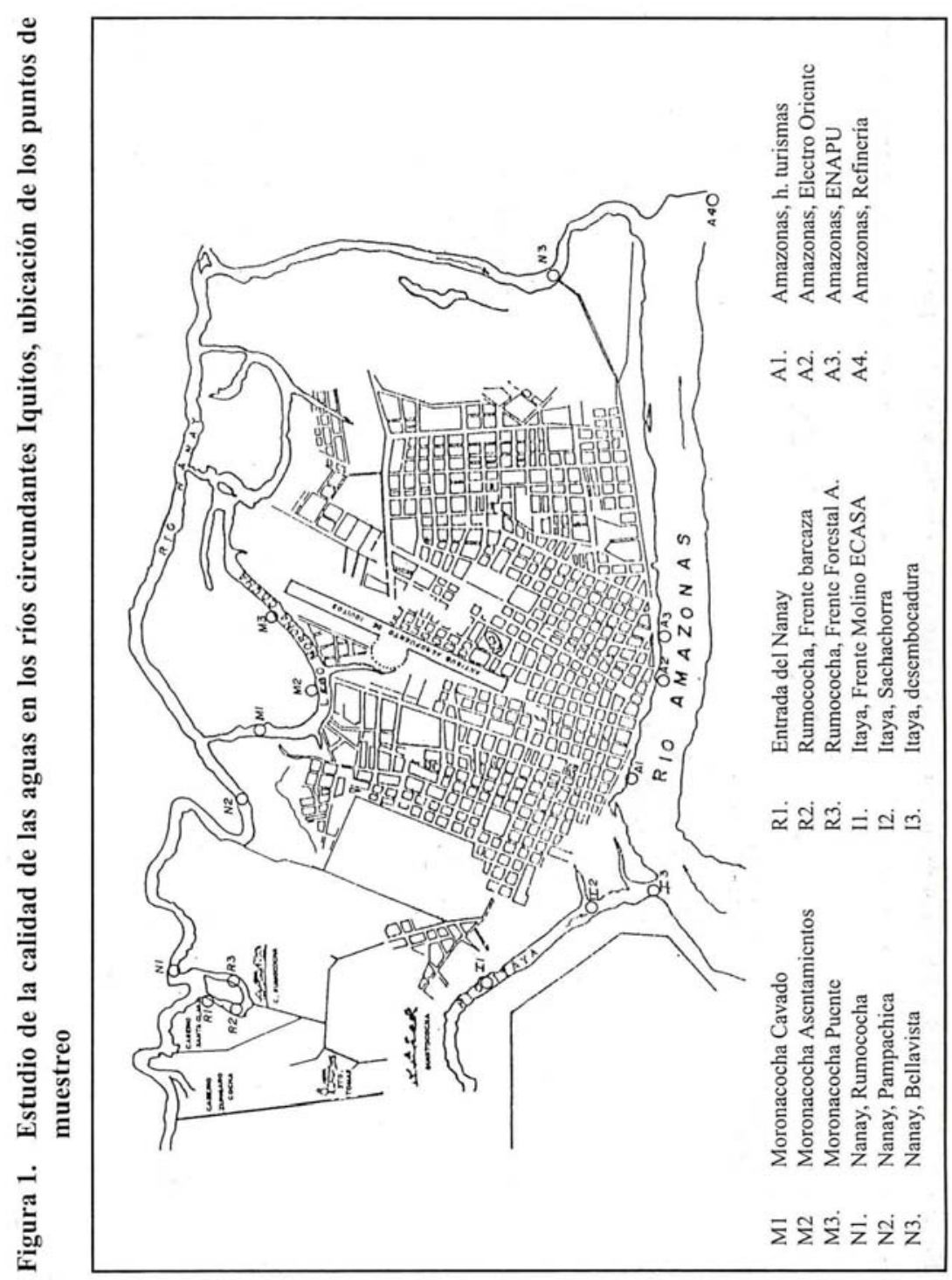




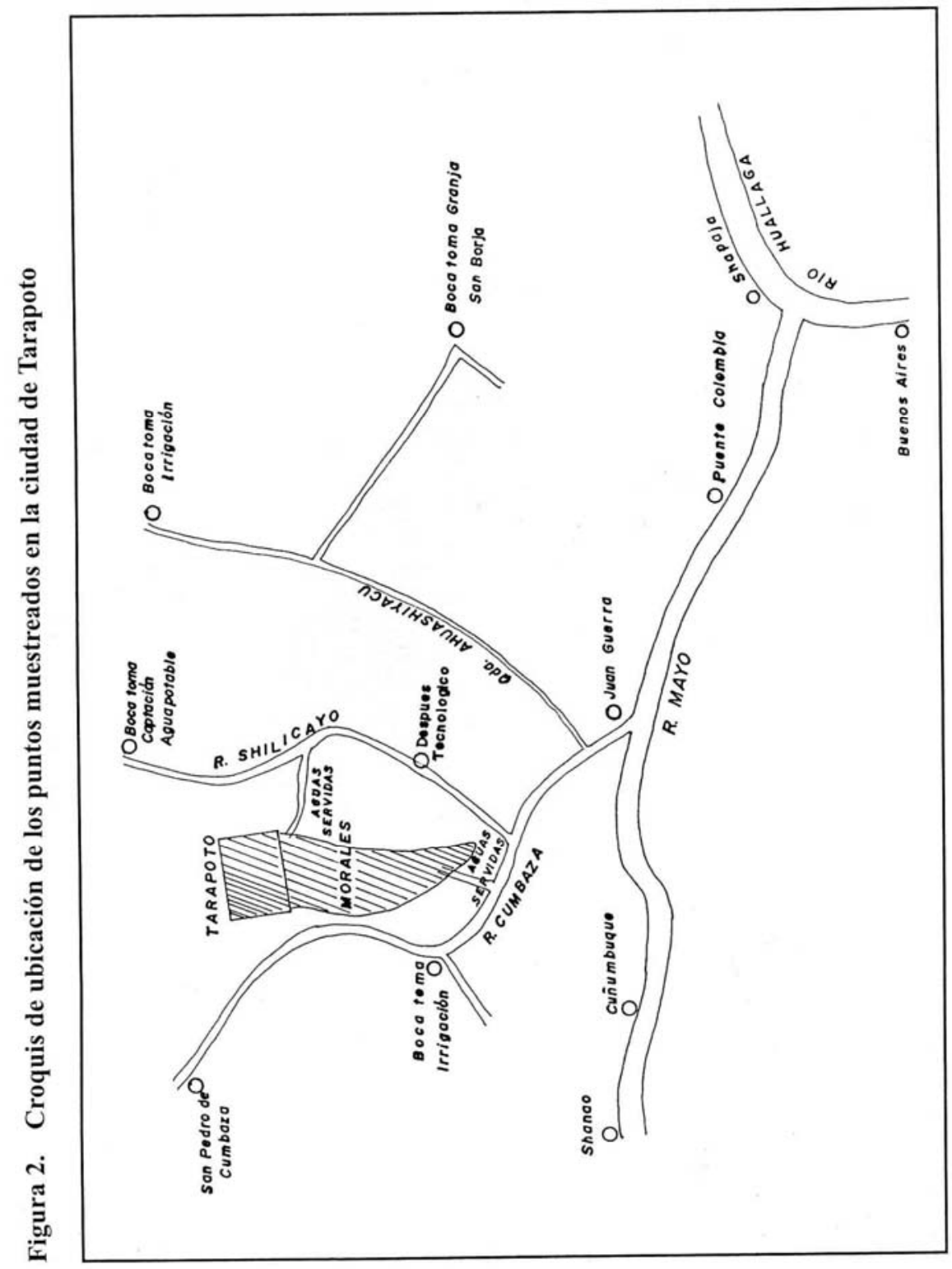




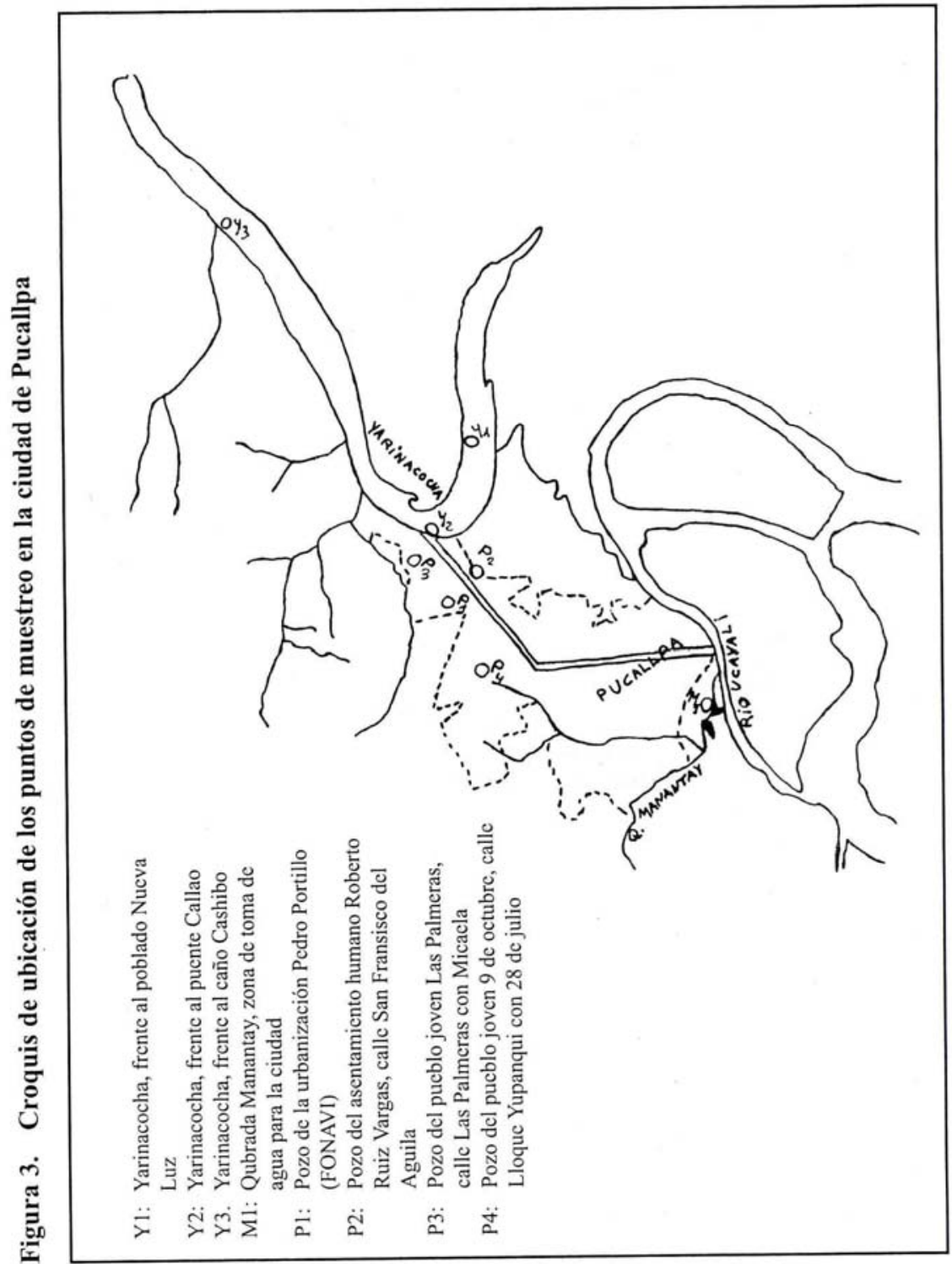

